Article

\title{
Functional Aspects of Early Light-Induced Protein (ELIP) Genes from the Desiccation-Tolerant Moss Syntrichia caninerois
}

\author{
Xiujin Liu 1,2,3®, Yigong Zhang ${ }^{1,2,3}$, Honglan Yang ${ }^{1,2,3}$, Yuqing Liang ${ }^{1,2,3}$, Xiaoshuang $\mathrm{Li}^{1,2,3}$, \\ Melvin J. Oliver ${ }^{4}$ and Daoyuan Zhang ${ }^{1,2,3, *(D)}$ \\ 1 CAS Key Laboratory of Biogeography and Bioresource in Arid Land, Xinjiang Institute of Ecology and \\ Geography, Urumqi 80031, China; liuxiujin14@mails.ucas.edu.cn (X.L.); zhangyigong203@163.com (Y.Z.); \\ yanghonglan@ms.xjb.ac.cn (H.Y.); liangyuqing14@mails.ucas.edu.cn (Y.L.); lixs@ms.xjb.ac.cn (X.L.) \\ 2 Turpan Eremophytes Botanical Garden, Chinese Academy of Sciences, Turpan 838008, China \\ 3 University of Chinese Academy of Sciences, Beijing 100049, China \\ 4 USDA-ARS-Plant Genetic Research Unit, University of Missouri, Columbia, MO 65211, USA; \\ Mel.Oliver@ARS.USDA.GOV \\ * Correspondence: zhangdy@ms.xjb.ac.cn; Tel.: +86-13899980890
}

Received: 10 December 2019; Accepted: 14 February 2020; Published: 19 February 2020

\begin{abstract}
The early light-induced proteins (ELIPs) are postulated to act as transient pigment-binding proteins that protect the chloroplast from photodamage caused by excessive light energy. Desert mosses such as Syntrichia caninervis, that are desiccation-tolerant and homoiochlorophyllous, are often exposed to high-light conditions when both hydrated and dry ELIP transcripts are accumulated in response to dehydration. To gain further insights into ELIP gene function in the moss S. caninervis, two ELIP cDNAs cloned from S. caninervis, ScELIP1 and ScELIP2 and both sequences were used as the basis of a transcript abundance assessment in plants exposed to high-light, UV-A, UV-B, red-light, and blue-light. ScELIPs were expressed separately in an Arabidopsis ELIP mutant Atelip. Transcript abundance for ScELIPS in gametophytes respond to each of the light treatments, in similar but not in identical ways. Ectopic expression of either ScELIPs protected PSII against photoinhibition and stabilized leaf chlorophyll content and thus partially complementing the loss of AtELIP2. Ectopic expression of ScELIPs also complements the germination phenotype of the mutant and improves protection of the photosynthetic apparatus of transgenic Arabidopsis from high-light stress. Our study extends knowledge of bryophyte photoprotection and provides further insight into the molecular mechanisms related to the function of ELIPs.
\end{abstract}

Keywords: ScELIP; high-light; photoprotection; photosynthesis

\section{Introduction}

Light is an essential energy source for all plant life and is used to generate a usable carbon-based energy source for growth via photosynthesis, however, when light intensities exceed the plant's saturated photosynthesis requirements it has the potential to cause damage to the plant [1]. This potential damage is driven by an overproduction of reactive oxygen species (ROS). The oxygen concentration in chloroplasts is governed by the activity of photosystem II (PSII) and the generation of ROS from the oxygen generated by PSII, e.g., $\mathrm{H}_{2} \mathrm{O}_{2}$, superoxide $\left(\mathrm{O}_{2}{ }^{-}\right)$, hydroxyl radicals, and ${ }^{1} \mathrm{O}_{2}{ }^{*}$ in chloroplasts is closely associated with exposure to excess light [2]. High-light intensities lead to an increase in ROS which, if not scavenged, will result in photo-oxidative damage and photoinhibition [3]. Photoinhibition in turn results in the degradation of carotenoids, bleaching of chlorophylls, and an increase in lipid peroxidation driven by the reactive-oxygen derivatives [4]. Photosynthetic organisms 
must thus find a balance between the requirements for efficient light harvesting and the danger of accumulating light-induced damage when light absorption exceeds the photosynthesis capacity.

Bryophytes, as one of the earliest diverging lineages of the extant land plants, are believed to have faced tremendous challenges in occupying a variety of ecological niches many of which were characterized by water deficits, high-light intensities, and increased exposure to UV radiation. In meeting these challenges bryophytes have evolved an efficient photosynthetic apparatus and photoprotection mechanisms. The drought-tolerant mosses, Rhytidium rugosum and Ceratodon purpureus, have demonstrably improved photosystem II (PSII) chlorophyll fluorescence quenching when dehydrated that is hypothesized to provide a means to dissipate excess excitation energy as heat [5]. The desert moss, Pterygoneurum lamellatum, exhibits damage to the photosynthetic apparatus that directly correlates to the rate of desiccation; $\mathrm{F}_{\mathrm{v}} / \mathrm{F}_{\mathrm{m}}$ values measured for gametophores dried slowly were similar to undried controls but were significantly reduced in plants dried quickly [6]. Syntrichia caninervis and Bryum argenteum, as predominant moss species of the Gobi Desert [7], rapidly reassemble thylakoid proteins during rehydration after a desiccation event, presumably as a means to recover photosynthesis and growth [8]. These mosses also quickly increase transcript abundance for genes involved in the light reactions, photorespiration, and other photosynthesis-related genes $[9,10]$, which presumably speeds the recovery of photosynthesis and carbon assimilation [11]. In Syntrichia caninervis, the increase in transcript abundance for genes involved in photosynthesis accompanies the rapid restoration and reorganization of PSII and increased chlorophyll synthesis [12].

To maintain normal function under high-light stress conditions plants induce light-stress proteins, the Early Light-Inducible Proteins (ELIPs), as part of the protective response [13]. ELIPs were initially described as proteins that were transiently expressed during greening of etiolated seedlings [14,15]. ELIPs are members of a closely related group of proteins that share highly conserved regions of homology: The three-helix ELIPS, the two-helix SEPS (stress-enhanced proteins), and the one-helix proteins (OHPs) along with HLIPS (high-light induced proteins), and SCPS (small Cab-like proteins) [16]. The Arabidopsis genome contains two ELIP genes, Elip1 and Elip2, both of which, along with light-induced greening, have been implicated in the control of seed germination, particularly when germination occurs under abiotic stress conditions [17]. ELIPs were also induced in mature green plants exposed to light stress in Arabidopsis [18] and are thought to play a role in photoprotection by transiently binding free chlorophyll preventing photo oxidative damage and facilitating energy dissipation that protects the PS-reaction center from photoinhibition [19].

The environmental responsiveness of ELIPs, as measured by transcript abundance, has been explored in many plants, primarily in angiosperms. ELIP cDNA clones have been constructed from RNA isolated from the alga D. salina [20], the bryophytes S. ruralis [21], and Physcomitrella patens [22], as well as a number of tracheophytes, including pea [23,24], barley [25], Arabidopsis [26], wheat [27], and the resurrection plant, Craterostigma plantagineum [28]. In addition to cases mentioned earlier, high-light stress induced accumulation of ELIP transcripts has been reported for pea [23,24], wheat [27], barley [25,29], grapevine [30], and Arabidopsis [26]. Low temperature can also induce ELIP gene transcript accumulation in pea [24], barely [25], cabbage [31], and Medicago sativa [32]. Salt stress can induce ELIP gene transcript accumulation in cabbage [31], Dunaliella salina [20], and Syntrichia ruralis [21]. In Madicago sativa [32], Arabidopsis [18], and S. ruralis [21] the ELIP transcript accumulates during dehydration. In all cases, the implication is that ELIPs play a major role in abiotic stress tolerance. This suggested role of ELIPs in abiotic stress tolerance mechanisms was recently strengthened by the observation that tandem proliferation of ELIP genes, coupled with the elevation of ELIP transcript abundance, is a distinctive feature of the genomes of resurrection plants [33].

In this report, we investigated ELIP transcript abundance in S. caninervis, a desiccation-tolerant moss, exposed to different light conditions. The aim was to provide further insights into the ability of ScELIPs to photo-protect photosynthetic capacity under light-stress conditions and to determine if light quality also impacted ELIP transcript abundance. In this study, we also investigated the functional ability of the ScELIPs to protect the photosynthetic machinery using an ectopic expression approach. 
The cDNA sequences were used to generate transgenic Arabidopsis Atelip mutants (lacking one of the AtELIP genes (AtELIP2) constitutively expressing the ScELIPs transcripts with the aim of assessing the ability of the ScELIPs to complement the Atelip mutant phenotype under different light treatments in different growth phases.

\section{Results}

\subsection{Multiple Sequence Alignment and Phylogenetic Analysis}

We identified 26 Unigenes as ScELIPs in the reference transcriptome [10], 6of which have complete open reading frames (ORFs): Unigenes 13021, 40120, 40121, 68225, 16576, and 8044. Unigene 16576 and 8044 each contain 94 predicted amino acids that were of short length to known ELIPs (Table S1). The predicted $\mathrm{pI}$ of Unigene 13021 was 5.58 which was significantly lower than other ScELIPs Unigenes. Unigenes 40121 and 68225 each contain ORFs that were of comparable length to known ELIPs and encode a putative primary amino acid sequence that matched known ELIP proteins. A multiple alignment of ScELIP with other ELIPs is shown in Supplementary Figure S1, ScELIPs have two conserved ELIP domains and exhibit conserved primary sequence regions to known ELIPs [34]. Unigenes 40121 and 68225 were chosen for generation of the target ELIP transgenes and were designated ScELIP1 and ScELIP2. ScELIP1 (GeneBank number KM363766) was 995-base pair (bp) in length and contained a 711 bp ORF encoding a 236 amino acid putative polypeptide. ScELIP2 (GeneBank number KM363767) was 904 bp in length and contained a 624 bp ORF encoding a 207 amino acid putative polypeptide as shown in Table 1.

Table 1. Properties of cloned ScELIPs ${ }^{1}$.

\begin{tabular}{lcc}
\hline \multicolumn{1}{c}{ Gene Name } & ScELIP1 & ScELIP2 $^{\mathbf{3}}$ \\
\hline Length of coding sequence (bp) & 995 & 904 \\
ORF (bp) & 711 & 624 \\
Predicted number of amino acids & 236 & 207 \\
Predicted molecular mass (kDa) & 25.68 & 21.69 \\
Predicted pI & 9.33 & 9.57 \\
\hline
\end{tabular}

1 The early light-induced protein of Syntrichia caninervis. ${ }^{2}$ The early light-induced protein gene 1 of Syntrichia caninervis. ${ }^{3}$ The early light-induced protein gene 2 of Syntrichia caninervis.

ScELIPs have one Chloroa_b-bind conserved domain like other known ELIPs (Figure 1). The Neighbor-Joining cladogram analysis (Figure 1) clustered ScELIP1 with other mosses ELIPS, such as SrELIPS (Syntrichia ruralis), PpELIPs (Physcomitrella patens), and SfELIP1 (Sphagnum fallax), liveworts ELIPs (Marchantia polymorpha), and ferns ELIPs (Onoclea sensibilis). ScELIP2, however, clustered with monocots and eudicots ELIPs, such as AtELIP1 and 2 (Arabidopsis thaliana), ZmELIP (Zea mays), OsELIP (Oryza sativa), GrELIP (Gossypium raimondii), and BrELIP (Brassica rapa).

\subsection{Gametophytic Expression of ScELIPs in Response to Light Treatments}

To elucidate whether a correlation exists between light quality and/or intensity with ScELIPS transcript abundance, the level of ScELIP1 and ScELIP2 transcripts were quantitatively assessed in total RNA from gametophytes of S.caninervis following exposure to various light regimes using RT-qPCR (Figure 2). ScELIP1 transcript abundance rapidly declines when the gametophytes are exposed to either UVA or UVB (Figure $2 \mathrm{a}, \mathrm{b}$ ) and does not recover from continued exposure to UVA but exhibits an ability to recover to approximately $50 \%$ of control abundance when exposed to UVB for $2 \mathrm{~h}$ but not after $4 \mathrm{~h}$ or $12 \mathrm{~h}$. ScELIP2 transcript abundance does not decline in response to exposure to either UVA or UVB but exhibits a peak increase in abundance at $4 \mathrm{~h}$ of exposure to UVA and after $2 \mathrm{~h}$ of exposure to UVB. In both treatments the level of abundance in the transcripts return to control levels at longer exposure times. 

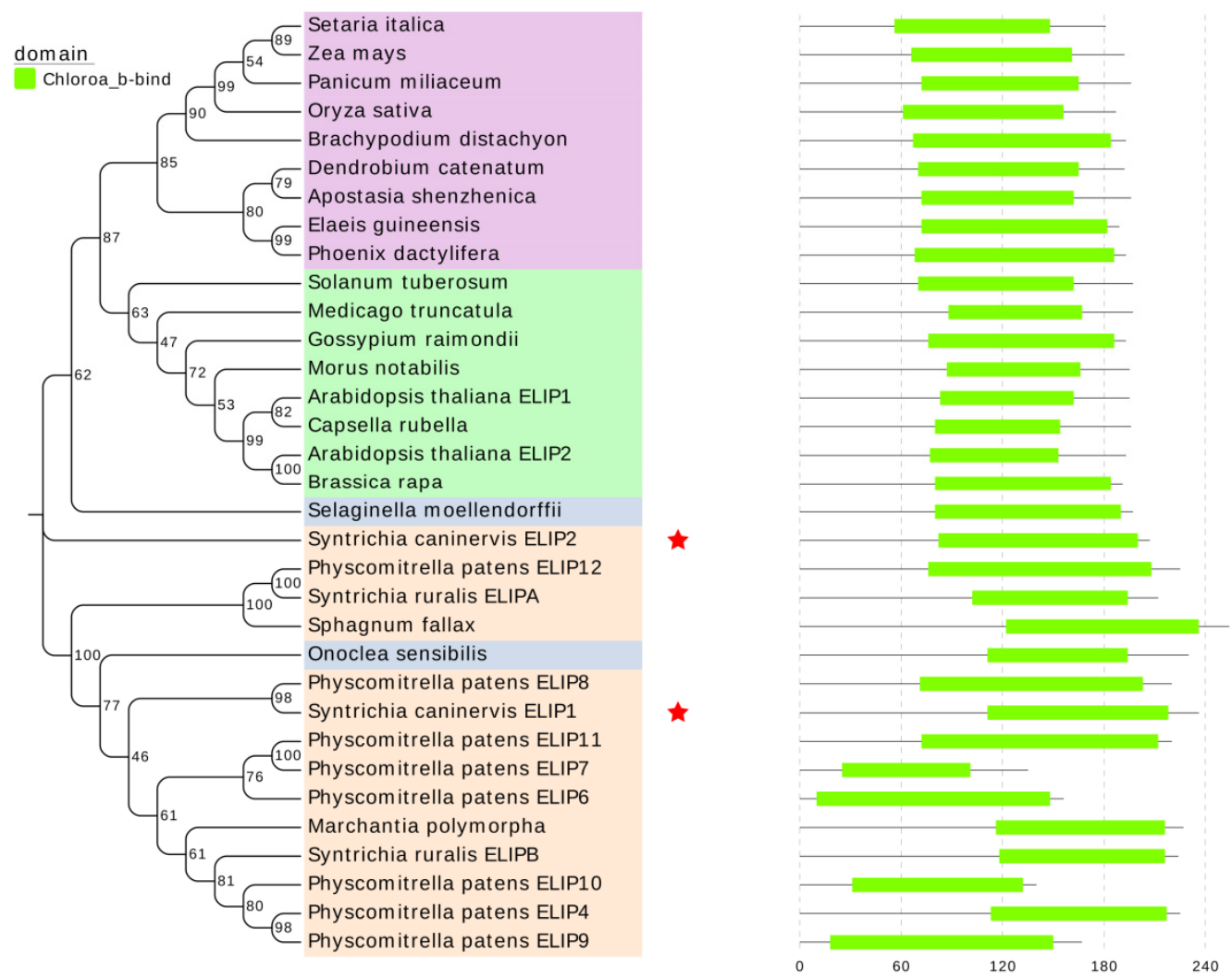

Figure 1. The phylogenetic tree inferred from the deduced protein sequence of ScELIPs and other 34 ELIP amid acid sequences represented by 24 additional taxa and conserved domain. In the left pannel, numbers above the lines represent bootstrap percentages (based on 1000 replicates). A bootstrap value of $100 \%$ indicates branches that were supported in all replicates of resampling of data. The scale bar indicates the number changes per unit length. The two ScELIPs were highlighted by a red star. Different colors represent different evolving groups, pink (bryophytes), blue (ferns), purple (monocots), and green (eudicots). In the right pannel, the conserved domain of ELIPs corresponding to the left pannel.

ScELIP1 transcript abundance increased 7-fold after $4 \mathrm{~h}$ of exposure to red-light (Figure 2c) and to similar levels in response to blue-light exposure after $4 \mathrm{~h}$ (Figure 2d). ScELIP2 transcript abundance only increased slightly in response to red-light and only after $4 \mathrm{~h}$ of exposure (Figure $2 \mathrm{c}$ ), but the transcript abundance steadily increased in response to prolonged exposure to blue-light (Figure 2d).

ScELIP1 transcript abundance increased approximately 5-fold after exposure to red-light for $2 \mathrm{~h}$ followed by blue-light for $2 \mathrm{~h}$ indicating that blue-light only dampened the response of ScELIP1 to red-light (Figure 2c). When the treatment was reversed, ScELIP1 transcript abundance was unaltered from control levels indicating that red-light prevented the transcript abundance response to blue-light (Figure 2d). ScELIP2 transcript abundance, in response to the identical dual light treatments, was elevated 15-fold with a $2 \mathrm{~h}$ exposure to red-light followed by $2 \mathrm{~h}$ of blue-light, but exhibited no response when $2 \mathrm{~h}$ of blue-light was followed by $2 \mathrm{~h}$ of red-light. Thus indicating, as for ScELIP1 transcript abundance, red-light inhibited the blue-light response.

The transcript abundance for both ScELIPS increase with increasing white light intensity. ScELIP1 transcript abundance increases linearly with increasing light intensity above $60 \mu \mathrm{mol} / \mathrm{m}^{2} / \mathrm{s}$ to a maximum abundance 9-fold higher than the dark control at $1500 \mu \mathrm{mol} / \mathrm{m}^{2} / \mathrm{s}$ (Figure 2e). ScELIP2 transcript abundance increases to a maximum level at 8-fold higher than the dark control at $750 \mu \mathrm{mol} / \mathrm{m}^{2} / \mathrm{s}$ but declined significantly when light intensity reached $1500 \mu \mathrm{mol} / \mathrm{m}^{2} / \mathrm{s}$ (Figure 2e). 

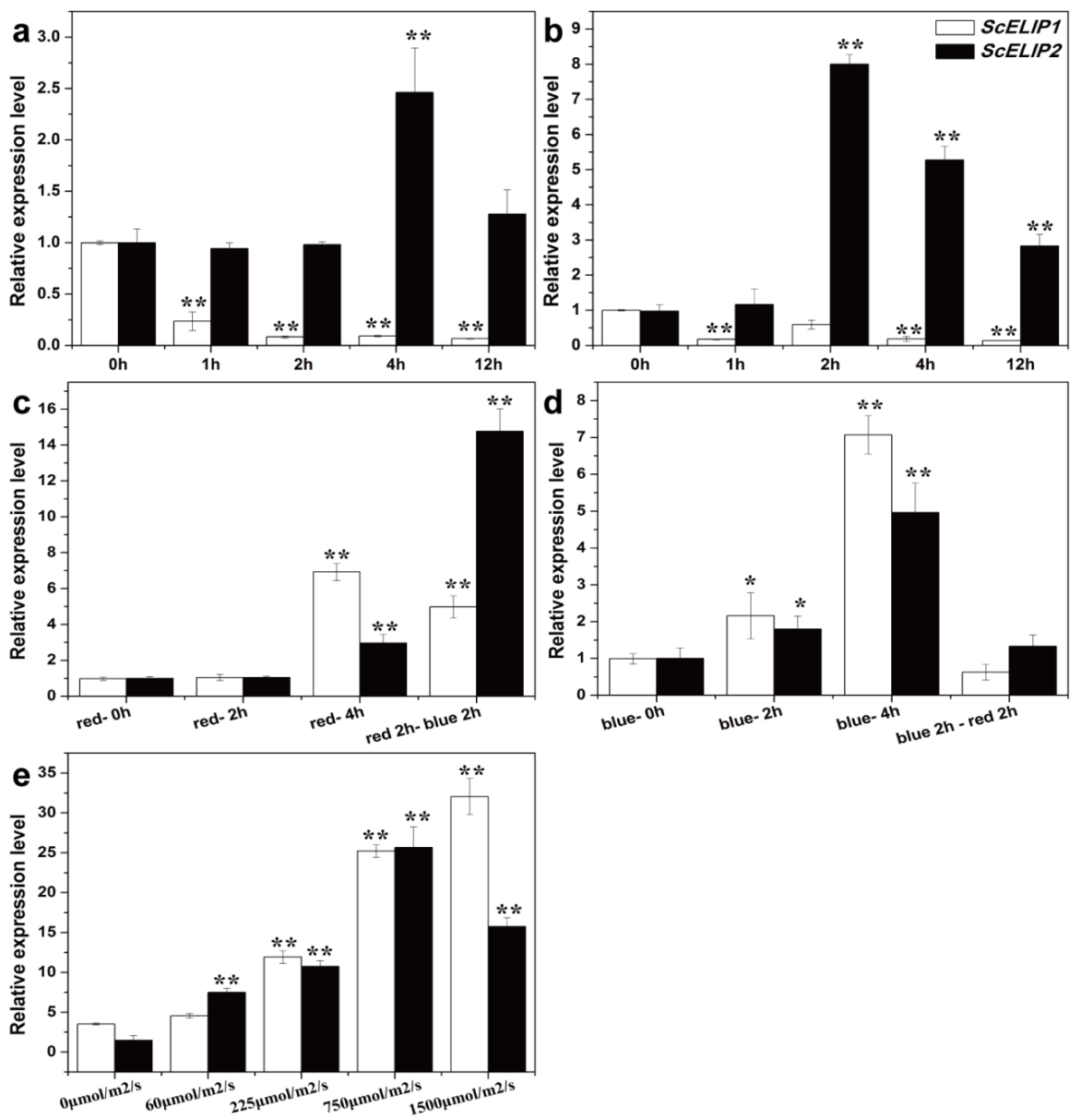

Figure 2. ScELIP1 and ScELIP2 transcript relative abundance assessments in Syntrichia caninervis gametophores exposed to various light treatments. The mean (each column) and SD (error bar) were calculated with three biological replicates and three technical replicates of each biological replicates. ${ }^{*} p<0.05 ;{ }^{* *} p<0.01$. P-values were obtained from Dunnett's T3 test comparing different time points and treatment with control. Asterisk represents statistically significant difference with $0 \mathrm{~h}$ in $(\mathbf{a}-\mathbf{d})$, and $0 \mu \mathrm{moL} / \mathrm{m}^{2} / \mathrm{s}$ in (e). ultra violet A (UVA) light treatment (a), ultra violet B (UVB) light treatment (b), red-light treatment $(\mathbf{c})$, blue-light treatment (d), high-light treatment (e).

\subsection{Transgenic Lines}

We obtained 15 ScELIP1 and 22 ScELIP2 transgenic T1 lines following the initial hygromycin screen of T0 transformants (Figures S4 and S5). RT-PCR and quantitative real time PCR validated transcript abundance of transgenic lines of ScELIPS (Figures S6 and S7), the transcript abundance of 35S-ScELIP1 and 35S-ScELIP2 transgenic lines were 5-fold to 23-fold higher than the Atelip mutant. In normal condition, there isn' $t$ 't visible phenotype difference between the Col-0 WT, the Atelip mutant, and the ScELIPs transgenic lines. Finally, we chose three transgenic lines of each gene construct that had significant expression levels, and named as SCELIP1-line 1, line 2, line 3, and ScELIP2-line 1, line 2, line 3.

\subsection{Germination and Early Seedling Growth under Different Light Treatments}

To assess the effect of the expression of ScELIP constructs on seed germination under different light stress conditions, germination performance and early seedling morphology was assessed over a seven-day period for mature seeds of the Col-0 WT, the Atelip mutant, and two of each of the 35S-ScELIP1 and 35S-ScELIP2 transgenic Atelip lines (Figure S8 and Figure 3). The Col-0 WT, Atelip mutant, and the two transgenic had no significant difference. The Col-0 WT and the two transgenic lines had 
significantly higher germination rates than the Atelip mutant until day 4 when red-light (Figure $3 c, d$ ) or blue-lightblue-light (Figure $3 \mathrm{e}, \mathrm{f}$ ) was used as the single light source. Germination under UVB light, the Col-0 WT had a significantly higher germination rate than either the Atelip mutant or the 35S-ScELIP transgenic lines, which had almost identical germination rates, up to 4 days after imbibition (Figure $3 \mathrm{~g}, \mathrm{~h}$ ). High-light irradiation $\left(1500 \mu \mathrm{mol} / \mathrm{m}^{2} / \mathrm{s}\right)$ resulted in a one-day delay of germination for all genotypes (Figure 3i,j). Under high-light, the germination rate for the Col-0 WT was faster than either the Atelip mutant or the 35S-ScELIP transgenic lines up to day 5, the germination rates for the 35S-ScELIP transgenic lines, however, were significantly faster than the Atelip mutant up to day 4 (Figure 3i,j). Expression of ScELIPs in the Atelip mutant increase germination rates but the rates do not attain WT rates when grown in red, blue, UVB, and high-light conditions.

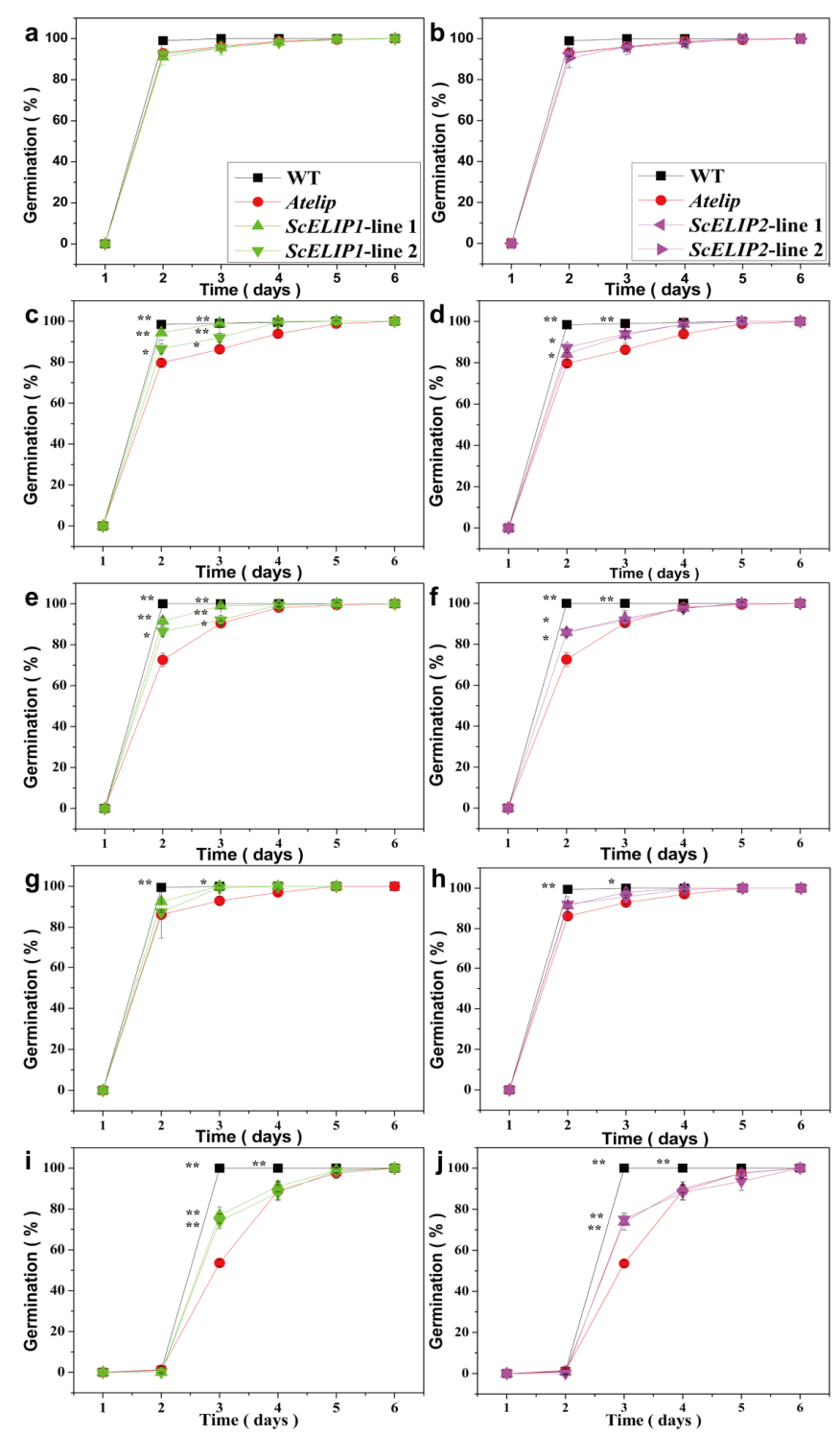

Figure 3. Seed germination rate for Col-0 WT (Arabidopsis thaliana L. cv. Columbia), Atelip mutant, and 35S-ScELIP lines under different light treatments. The graphs depict germination rates over six days exposure to the different light regimes: Control condition $(\mathbf{a}, \mathbf{b})$, Red-light alone (c,d), Blue-light alone (e,f), UVB light alone (g,h), High-light irradiation $\left(1500 \mu \mathrm{mol} / \mathrm{m}^{2} / \mathrm{s}, \mathbf{i}, \mathbf{j}\right)$. Error bars represent the SD (standard deviations) of three biological repeats. ${ }^{*} p<0.05 ;{ }^{* *} p<0.01$. P-values were obtained from Dunnett's T3 test comparing WT and the transgenic lines with the Atelip mutant, respectively. First set, 35S-ScELIP1 line 1 and line 2; Second set, 35S-ScELIP2 line 1 and line 2. 
Exposure to light from each of the sole light sources altered the initial seedling morphology in all genotypes: Red-light severely reduced the size of seedlings and caused hypocotyls elongation, blue-lightblue-light enlarged cotyledons and extended hypocotyls, UVB light resulted in failure of the cotyledons to open and a shortened hypocotyl, and high-light resulted in reduced hypocotyl extension as shown in Figure S8.

\subsection{Light Treatment Effects on 7-Day Old Seedling Growth and Morphology}

Seven-day old seedlings of the Col-0 WT, Atelip mutant, and 35S-ScELIP1 and 35S-ScELIP2 transgenic lines were exposed to 4 different light treatments; control conditions, red-light only, blue-light only, and UVB light for seven days and the resulting phenotypes were recorded (Figure S9) and growth parameters quantified (Figure 4). Under normal conditions, the Col-0 WT, Atelip, and transgenic lines showed no difference in seedling morphology (Figure S9a,e). Under red-light alone, the number of leaves (Figure 4c) and overall root lengths (Figure 4a) were reduced in comparison to the controls and equally for all of the genotypes, only root number (Figure $4 \mathrm{~b}$ ) was unaffected by the red-light treatment. The red-light treatment also caused etiolation of the leaves (Figure S9b,f) and reduced the chlorophyll content (Figure 4d). Under blue-light alone, the overall root length was significantly reduced for all genotypes compared to the control (Figure 4a). Conversely, the seven- day exposure to blue-light resulted in an approximate ten-fold increase in secondary root and the increase was significantly greater for the Atelip mutant and the 35S-ScELIP transgenics (Figure S9c,g and Figure 4b). Exposure to blue-light also resulted in chlorosis of the leaves of the Col-0 WT with a concurrent reduction in chlorophyll, however, the Atelip mutant and the 35S-ScELIP transgenics remained green and the chlorophyll content was only reduced to approximately $50 \%$ of the controls (Figure 4d). The UVB treatments inhibited seedlings growth in all genotypes with large reductions in root length and leaf number (Figure S9d,h and Figure 4a,c). The leaf chlorophyll contents also declined when compared to controls but the seedlings remained green for all genotypes (Figure $4 \mathrm{~d}$ ).
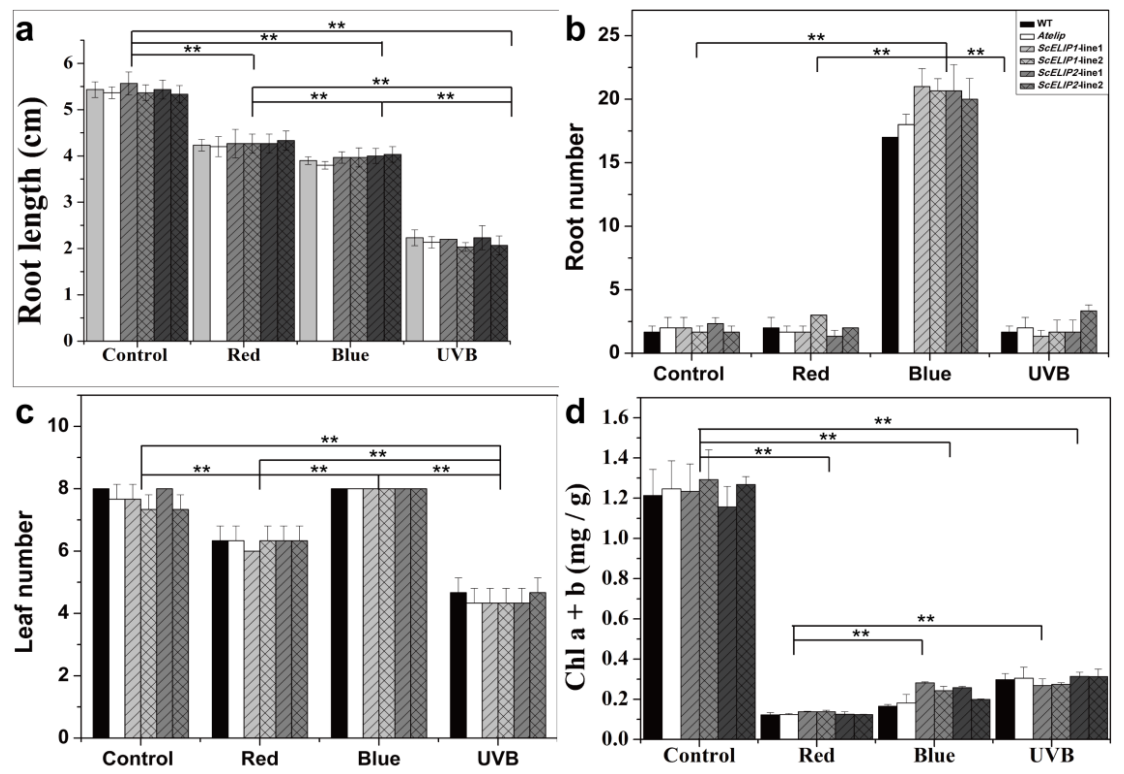

Figure 4. Morphological responses of Col-0 WT, Atelip mutant, and 35S-ScELIP transgenic seedlings to different light regimes. Panel (a), root length in centimeter $(\mathrm{cm})$; panel $(\mathbf{b})$, root number; panel (c), leaf number; panel (d), Total chlorophyll content in milligram (mg) per gram fresh weight. Error bars represent the SD of three biological repeats. ${ }^{* *} p<0.01$, P-values were obtained from Dunnett's T3 test comparing the 35-SScELIP lines with Atelip mutant. P-values also were obtained from Dunnett's T3 test comparing the control (normal light condition), red, blue, and UVB light with each other. Asterisk represents statistically significant difference within one group or among specific groups delineated by the brackets. 


\subsection{Seedling Growth of WT and Transgenic Lines under High-Light Conditions}

Seven-day old seedlings of the Col-0 WT, Atelip mutant, and transgenic lines were exposed to high-light stress $\left(1500 \mu \mathrm{mol} / \mathrm{m}^{2} / \mathrm{s}\right)$, and morphology and the chlorophyll contents were monitored after $2 \mathrm{~h}$ exposure and $24 \mathrm{~h}$ recovery $22 \pm 2{ }^{\circ} \mathrm{C}$ with a $14 \mathrm{~h}$ light $/ 10 \mathrm{~h}$ dark cycle, and $60-75 \%$ relative humidity, and light at PPFD of $100 \mu \mathrm{mol} / \mathrm{m}^{2} / \mathrm{s}$ (Figure 5). Following the high-light exposure, the transgenic lines appeared greener than the Col-0 WT and Atelip (Figure 5a,b) which was reflected in the chlorophyll contents that were significantly increased (Figure 5 c). Corresponding with chlorophyll contents, carotenoid contents of the transgenic lines were significantly higher than the Col-0 WT and Atelip mutant (Figure 5d).
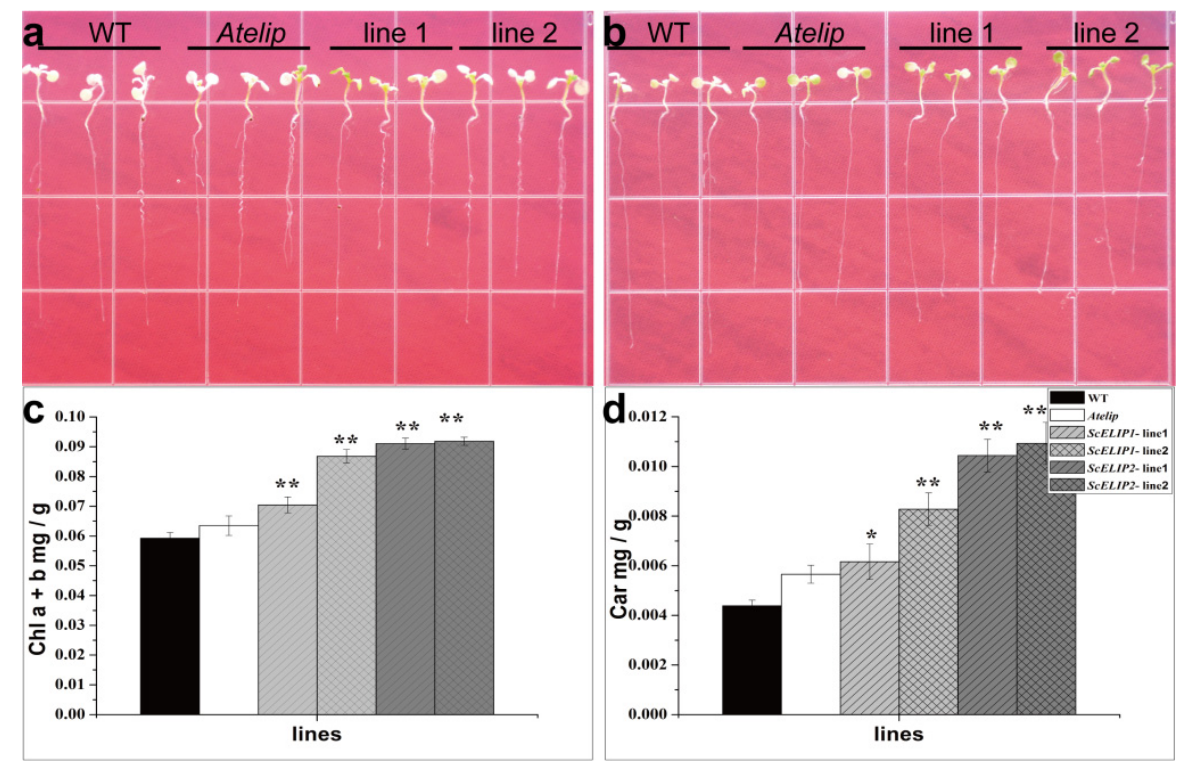

Figure 5. Phenotypic response of Col-0 WT, the Atelip mutant, and 35S-ScELIP1 and 35S-ScELIP2 transgenics to high-light irradiation $(1500 \mu \mathrm{mol} / \mathrm{m} 2 / \mathrm{s})$ for $2 \mathrm{~h}$ and recovery for $24 \mathrm{~h}$ under control conditions. (a) Col-0 WT, Atelip, and 35S-ScELIP1; (b) Col-0 WT, Atelip, and 35S-ScELIP2; (c) Chlorophyll content of Col-0 WT, Atelip, and 35S-ScELIP transgenics after exposure to $2 \mathrm{~h}$ of high-light irradiation followed by $24 \mathrm{~h}$ of recovery in control conditions; (d) Carotenoid content of Col-0 WT, Atelip, and $35 S-S c E L I P$ transgenics after exposure to $2 \mathrm{~h}$ of high-light irradiation followed by $24 \mathrm{~h}$ of recovery in control conditions.

\subsection{The Effect of High-Light Stress on Arabidopsis Plantlets}

Four-week old Arabidopsis plantlets, including WT, Atelip mutant, and two transgenic lines of ScELIP1 and ScELIP2, were exposed to high-light stress $\left(1000 \mu \mathrm{mol} / \mathrm{m}^{2} / \mathrm{s}\right)$ for 3 days and continuously for 3 weeks. The effect of high light appears to be more severe in the Atelip mutant line after the 3-day treatment than the Col-0 WT and all of the 35S-ScELIP transgenic lines (Figure 6). All genotypes were severely affected by 3 weeks of exposure to high-light, although the Atelip mutant does appear to be more severely damaged.

The chlorophyll fluorescence parameters measured were consistent with visual estimates of leaf damage. The 3-day high-light treatment resulted in a significant decline in the $\mathrm{F}_{\mathrm{v}} / \mathrm{F}_{\mathrm{m}}$ values (Figure 7) indicative of an inhibition photosynthesis under high-light stress. After 3 days of high-light treatment, the $F_{v} / F_{m}$ values were so low as to be unreliable and/or undetectable so this data was not added to the analysis. The chlorophyll fluorescent parameters decreased as the stress time extend in all Arabidopsis, it indicated that high-light increased the decline of parameters, the PSII complex have been photo-inactivated, and chlorophyll began to degrade (Figure 6 and Figure S10), a severely compromised photosynthetic apparatus. However, the 35S-ScELIPS lines exhibit a higher retention of the $\mathrm{F}_{\mathrm{v}} / \mathrm{F}_{\mathrm{m}}$ 
(Figure 7), indicating an increase in protection from photo-induced inactivation and thus potentially overcoming the lack of the ELIP2 gene product that is missing in the Atelip mutant.
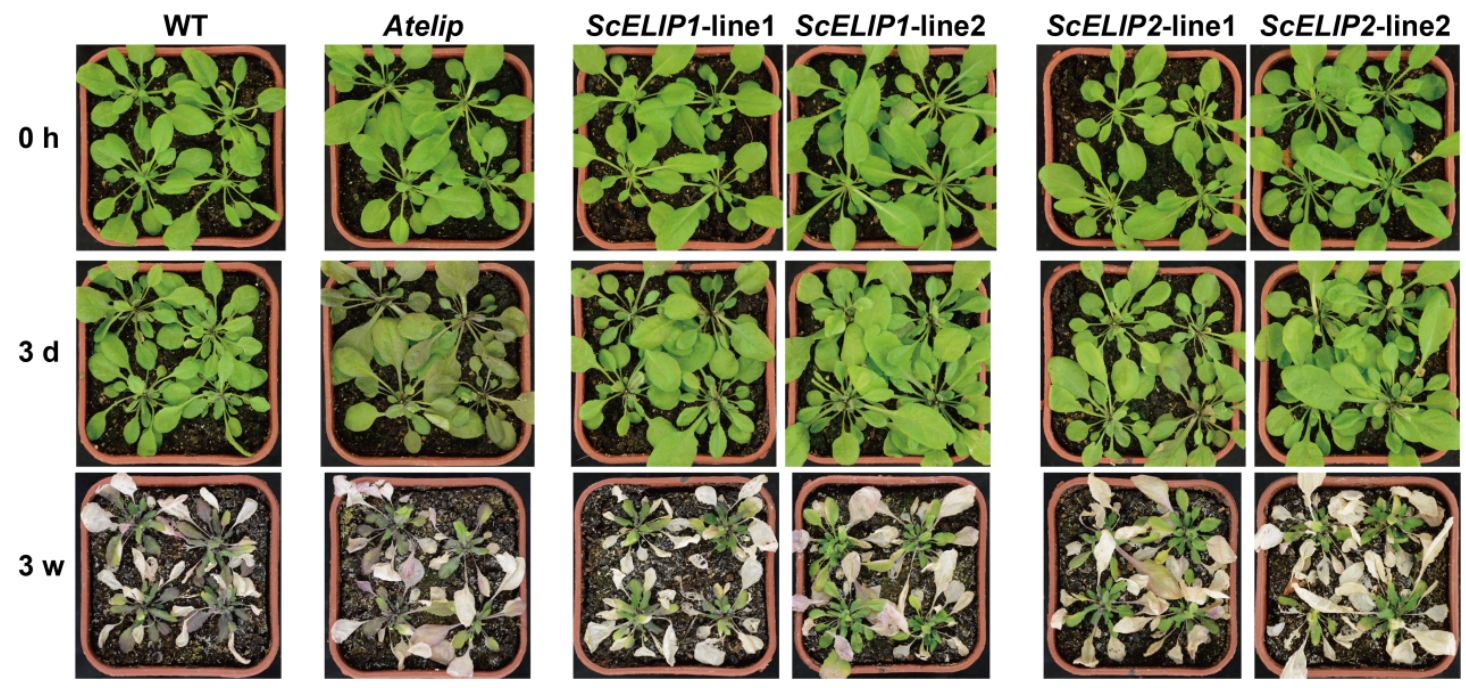

Figure 6. Phenotypic response to high-light exposure for Col-0 WT, Atelip, and 35S-ScELIP1, and 35S-ScELIP2 plantlets. Four-week old Arabidopisis lines prior to high-light irradiation treatment (Row 1), at 3 days of high-light irradiation $\left(1000 \mu \mathrm{mol} / \mathrm{m}^{2} / \mathrm{s}\right)$ treatment (Row 2), and 3 weeks of continuous high-light irradiation $\left(1000 \mu \mathrm{mol} / \mathrm{m}^{2} / \mathrm{s}\right)$ (Row 3).

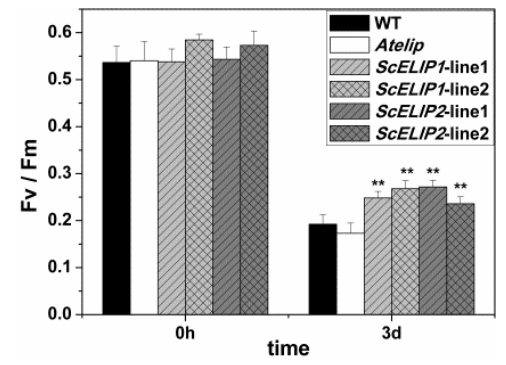

Figure 7. Photosynthetic parameters for WT, Atelip, and 35S-ScELIP1 or 35S-ScELIP2 at $0 \mathrm{~h}$ (prior to treatment) and 3 days of high-light exposure $\left(1000 \mu \mathrm{mol} / \mathrm{m}^{2} / \mathrm{s}\right)$. Error bars represent the SD of three biological repeats. ${ }^{* *} p<0.01$, P-values were obtained from Dunnett's T3 test comparing WT and the transgenic lines with the Atelip mutant, respectively. Fv/Fm: Maximal quantum yield of PSII, Y(II): Actual quantum yield of PSII, ETR: Photosynthetic electron transport rate.

Pigment contents were measured prior to the treatment (time zero), after 3 days and after 3 weeks of the high-light treatment. Both chlorophyll $\mathrm{a}$ and $\mathrm{b}$ and carotenoid contents decreased in both the 3-day and 3-week treatments with high-light (Figure S10a-d). Although, the pigment content of the $35 S-S c E L I P s$ lines were not elevated with respect to the Col-0 WT controls they were significantly greater than the levels measured in the Atelip mutant line, indicating that the 35S-ScELIPs constructs can rescue the Atelip mutant with regards to the effect of a lack of ELIP2 on high-light induced photodamage and pigment loss. The apparent rescue of the effect of the Atelip mutation on photosynthetic capacity is also reflected in the overall restoration of the $\mathrm{Chla} / \mathrm{Chlb}$ and $\mathrm{Car} / \mathrm{Chl}$ ratio of all 35S-ScELIPS (Figure S10d-e).

Transcript abundance was assessed for ScELIP1 and ScELIP2 and other photosynthesis related genes, in all genotypes, before treatment $(0 \mathrm{~h})$, after $2 \mathrm{~h}, 3$ days, and 3 weeks exposure to high-light stress using RT-qPCR (Figure 8). ScELIP1 and ScELIP2 exhibit moderate levels in the controls $(0 \mathrm{~h})$, presumably indicating the level of expression obtained with the $35 S$ promoter. ScELIP1 transcript abundance rapidly increased 35-70-fold in the 35S-ScELIP1 lines following exposure to high-light for $2 \mathrm{~h}$ but subsequently declines to low abundance after 3 days and negligible levels after 3 weeks of exposure to high-light (Figure 8a). ScELIP2 transcripts rapidly declined in abundance upon exposure of the 
35S-ScELIP2 transgenic to high-light, however, ScELIP2 transcript abundance significantly increased to 49-69-fold in response to prolonged exposure to high-light for 3 weeks (Figure 8b). ScELIP2 transcripts did not accumulate to significant levels in the Col-0 WT even after exposure to high-light for 3 weeks.
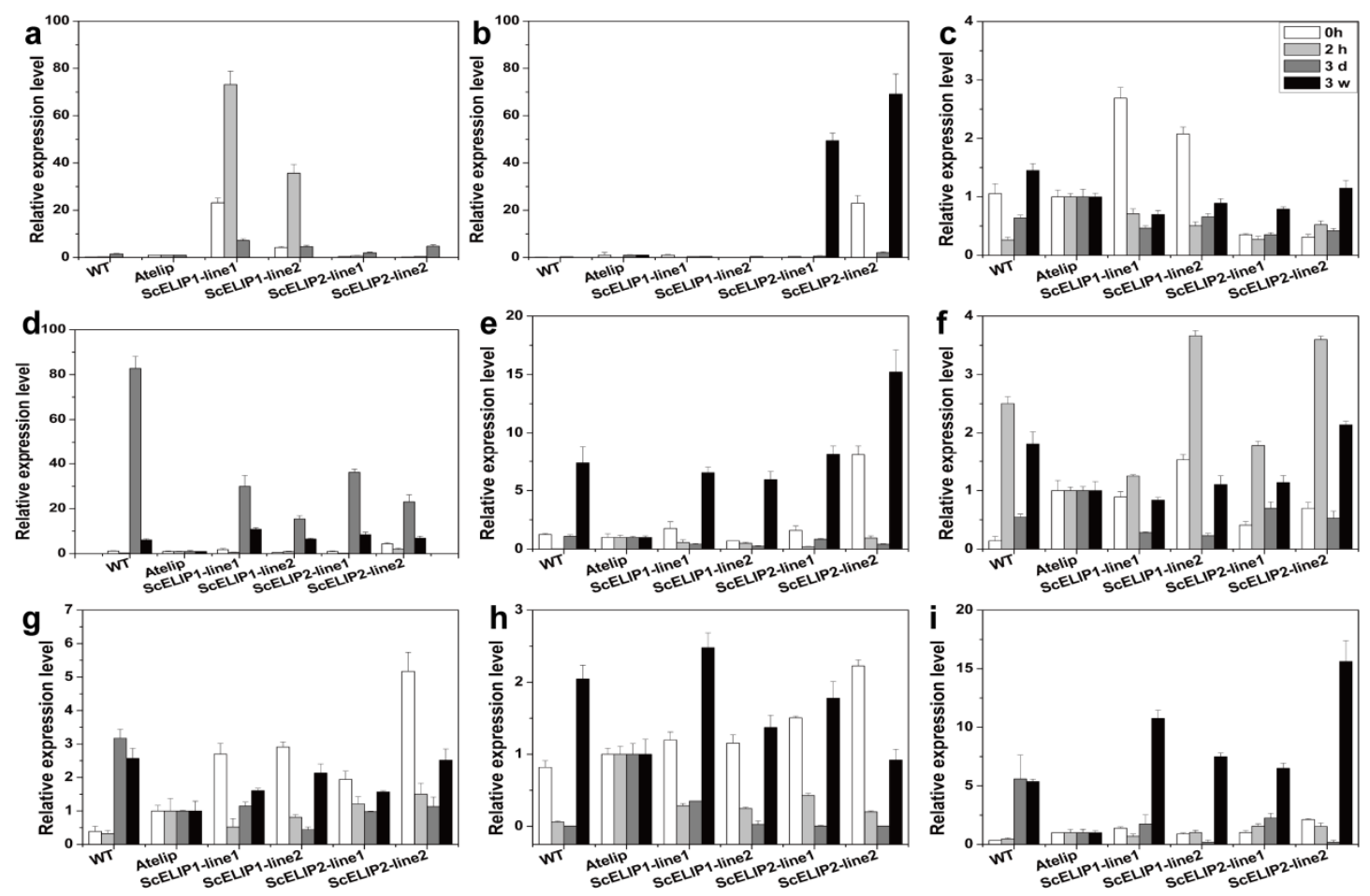

Figure 8. Twelve photosynthesis genes transcript relative abundance assessments in Arabidopsis thaliana different genotypes (WT, Atelip, transgenic lines) exposed to high-light treatments $\left(1000 \mu \mathrm{mol} / \mathrm{m}^{2} / \mathrm{s}\right)$ for various times. Error bars represent the SD of three biological repeats. Relative expression values were obtained from $2^{-\Delta \Delta C t}$ comparing WT and the transgenic lines with the Atelip mutant, respectively. ScELIP1: The inserted S. caninervis ELIP1 coding sequence (a), ScELIP2: The inserted S. caninervis ELIP2 coding sequence (b), PSBS: The native Arabidopsis PSII CP22 protein gene (PSBS) transcript (c), $O H P$ : The native Arabidopsis one-helix protein gene (OHP) transcript (d), OHP2: The native Arabidopsis one-helix protein 2 gene (OHP2) transcript (e), SEP2: The native Arabidopsis two-helix protein gene (SEP) transcript (f), LHCA2: The native Arabidopsis PSI antenna protein gene (LHCA2) transcript (g), LHCB4.2: The native Arabidopsis PSII CP29 antenna protein gene (LHCB4.2) transcript (h), PSBD: The native Arabidopsis PSII D2 protein gene (PSBD) transcript (i).

Transcript abundance for 3 of the AtELIP family of related proteins were also altered in response to high-light. The abundance of $O H P$ transcripts peaked at 3 days of exposure to high-light in Col-0 WT and also in the 35S-ScELIPs lines but to a lesser extent. The OHP transcripts in the 35S-ScELIPS lines were significantly more abundant than the same transcript in the Atelip mutant. In all cases OHP transcripts declined in abundance at 3 weeks (Figure $8 \mathrm{~d}$ ). OHP2 transcripts accumulate to levels 5-15-fold greater than control levels $(0 \mathrm{~h})$ in the Col-0 WT and 35S-ScELIPs lines after 3 weeks of exposure to high-light and to levels significantly greater than in the Atelip mutant (Figure 8e). SEP2 transcripts increased in abundance after exposure to high-light for $2 \mathrm{~h}$ in the Col-0 WT and 35S-ScELIPs lines, in both cases to higher levels than in the Atelip mutant, declined after 3 days of high-light exposure and then returned to near control levels after 3 weeks (Figure 8f).

LHCA2 transcripts declined in abundance response to exposure to high-light at $2 \mathrm{~h}$ and 3 days, and slightly increased at 3 weeks in the 35S-ScELIP lines. However, in the Col-0 WT LHCA2 transcripts increased in abundance after 3 days of high-light exposure and remained high throughout the length of the treatment (Figure 8g). LHCB4.2 transcript abundance in the Atelip mutant, 
remained constant throughout the 3-week exposure to high-light. In the Col-0 WT and both transgenic lines, LHCB4. 2 transcript abundance declined during the first 3 days of exposure to high-light but was dramatically elevated in abundance in the samples exposed for 3 weeks (Figure $8 \mathrm{~h}$ ).

In the Col-0 WT, PSBD transcript abundance was elevated 5-fold after 3 days of exposure and remained elevated throughout the high-light treatment but in the 35S-ScELIP transgenic lines PSBD transcripts only accumulated to elevated levels in the 3-week exposure samples. The PSBD transcript abundance in the Atelip mutant remained at relatively low levels throughout the treatment (Figure 8i). PSBS transcript abundance initially high in the control leaves of the 35S-ScELIP1 lines declined in response to exposure to high-light with a moderate recovery at 3 weeks. PSBS transcript abundance in the control Col-0 WT exhibited a similar response to that of the 35S-ScELIP1 lines but made a full recovery at 3 weeks. In the 35S-ScELIP2 lines, PSBS transcript abundance maintained initial levels through the first 3 days of exposure to highlight but were significantly elevated above control levels at 3 weeks (Figure 8c).

\section{Discussion}

In this study, we identified and characterized two ELIP genes from the S. caninervis transcriptome. ScELIP1 has close primary amino acid sequence similarity to the ELIPS of the non-vascular plants Physcomitrella patens, Sphagnum fallax, and Syntrichia ruralis [21] excepting one kind of fern (Onoclea sensibilis). ScELIP2 that is more similar to the ELIPs of vascular plants such as Arabidopsis [26], Zea mays [35], etc. (Figure 1). According to the amino acid sequence similarity of ELIPs, bryophytes ELIPs were clearly separated from monocots and eudicots ELIPs, because bryophytes are a special evolutionary group. Neither of the ScELIP sequences fully corresponds to either of the two Arabidopsis ELIP genes which, by ectopically expressing the ScELIP genes independently in the Arabidopsis Atelip mutant background, allowed us to evaluate both the possible activity of the ScELIP transcripts in photoprotection of chloroplasts in situ but also to determine if the moss ELIPs could rescue the Atelip phenotype resulting from the loss of AtELIP2.

In Syntrichia caninervis ScELIP1 and ScELIP2 transcripts abundance were elevated by different light stresses (Figure 2). ScELIP1 and ScELIP2 transcripts exhibit similar responses, both exhibit greater accumulation in response to blue and high-light exposure and both exhibit transcript accumulation only after a $4 \mathrm{~h}$ exposure to red-light, more evident for ScELIP1. Our understanding of how or why ELIPS respond to different light qualities is still very limited, but in pea seedlings ELIPs transcripts are specifically induced by blue-light but not by red-light, and the accumulation of blue-light induced ScELIPs transcripts are significantly repressed by low intensity red-light [23]. These findings are consistent with the $S$. caninervis data presented here with the exception that prolonged exposure to red-light alone does result in an elevation ScELIP transcript abundance. The two Arabidopsis ELIP genes can be induced in dark grown Arabidopsis exposed to illumination by high intensities of both red and blue-light [18] which again are consistent with observations. In Arabidopsis, ELIP transcript abundance was elevated by UVA but not by UVB [36]. In S. caninervis, ScELIP1 transcripts declined in abundance in response to UVA and ScELIP2 transcript levels only exhibited a response to UVA after a $4 \mathrm{~h}$ exposure (Figure 2a). UVB exposure caused a general decline in ScELIP1 transcripts but generated an increase in abundance of ScELIP2 transcripts after $2 \mathrm{~h}$ of exposure. Clearly, the S. caninervis ELIP response to UV light differs from that seen in Arabidopsis, perhaps indicating a more complex role in UV protection mechanisms in the moss. However, this possibility must be tempered by differences in experimental protocols and by the distinct possibility that the moss genome contains more than two ELIP genes as would be suggested by the observation that the genomes of desiccation tolerant plants are rich in ELIP genes [33].

It is clear from our analyses that ELIP transcript abundance in S. caninervis is altered by light quality (UVA and B, red and blue-light), suggesting that the promoters that control the transcription of ELIP genes contain elements that respond to light signal transduction pathways. At the present time, the promoter sequences for the S. caninervis ELIP genes are unavailable but ELIP promoters from other 
species have been investigated. In Ginkgo biloba, high-light defense and stress responsive elements were delineated in the promoter region of GbELIP [37]. In Arabidopsis, ELIP1 expression is enhanced by red, far-red, and blue-light and that phytochrome A and B are involved in the signaling pathway along with the transcription factor HY5 [18]. The Arabidopsis ELIP2 promoter region was later demonstrated to contain two regulatory elements, that form a regulatory unit, that regulate ELIP2 expression in response to UVB, high-light, and cold stress [38]. If similar elements appear, the ScELIP promoter might add to our understanding of the evolution of light response transduction pathways in plants.

The significant and rapid elevation in the ScELIPs transcript abundances when gametophytes are transferred from the dark to high-light is consistent with similar observations in Arabidopsis [39], Hordeum vulgare [25], Pisum sativum [23], D. salina [20], and Syntrichia ruralis [21] and supportive of the hypothesis that ELIPs are useful indicators of high-light stress and the initiation of photoprotection mechanisms during the early phases of photodamage [40].

Light stress has been demonstrated to exert influence on seed germination and photomorphogenesis during the initial developmental stages of seedling growth [17]. Our results supported the observation that light quality alters photomorphogenesis following germination (Supplementary Figure S8) such that the hypocotyl was shortened and the cytoledons remained closed following germination under UVB light [41]. In a recent report, UVB photoreceptor UVR8 (UV resistance locus 8 ) promotes rapid PIF (phytochrome interacting factors) degradation and reduces PIF abundance, which lead to UVB inhibits shade avoidance, finally, UVB inhibits stem elongation of Sharma et al. [42]. While this phenotype was not altered by the expression of the 35S-ScELIPs in the transgenic seeds. The addition of the 35S-ScELIPs genes into the Atelip mutant line significantly improved the germination rate above that of the mutant alone without altering leaf number, root number, or root length with the exception of an increase in root number in the 35S-ScELIP transgenics under blue-light (Figure 4).

The complementation of the 35S-ScELIP genes to the Atelip mutant line enhanced the survival rate of seedlings under high-light stress in part by minimizing chlorophyll degradation. The transgenic lines, by protecting the chlorophyll, were greener in appearance than even the Col-0 WT lines after $24 \mathrm{~h}$ of recovery following exposure to high-light conditions and also had a higher percent survival (Figure 5). This was also evident in the more mature plant, where the transgenic lines exhibited significantly less photodamage under prolonged exposure to high-light intensities than the mutant line (Figure 6). The improved protection to photodamage observed in the 35S-ScELIP transgenics was reflected in their improved photosynthetic performance measures compared to the Atelip mutant increased $\mathrm{F}_{\mathrm{v}} / \mathrm{F}_{\mathrm{m}}$ (Figure 7). These data suggest that the ScELIPS can protect PSII functionality of Arabidopsis plantlets under high-light conditions. ELIP accumulation under high-light stress has been correlated with photoinhibition of PS, degradation of the D1 protein, and changes in the level of pigments in the mature plant $[36,43]$. These conclusions are consistent with our data indicating enhanced PSII protection in the 35S-ScELIP transgenics.

The results of this study indicate that the physiological function of ELIPs are related to the protection of chlorophyll, and thus enhance the protection of the chloroplasts from photooxidative stress. The 35S-ScELIP1 and 35S-ScELIP2 lines also have improved carotenoid levels than those recorded for the Atelip mutant following high-light exposure and thus it is possible that ScELIPs may also play a role in stabilizing the photosynthetic apparatus and is consistent with the idea that ELIP acts as a photoprotectant for PSII in the thylakoid membrane and as such would play a major role in the ability of Syntrichia caninervis to survive in extreme conditions, as suggested by VanBuren et al. [33], and that it regularly encounters in the Gobi Desert.

The 35S-ScELIP1 and 35S-ScELIP2 lines have a significant response to high-light (Figure 8a,b) even though their transcription is controlled by the $35 S$ promoter. It is possible that the overall transcription rates affected by high-light or transcript abundance under high-light is partially controlled by transcript stability. The former seems unlikely given the variability in transcript abundance for other genes in response to high-light (Figure 8). It is possible that transcript abundance was controlled in part by the 
altered stability but this possibility was not investigated. It is also possible that the $35 \mathrm{~S}$ promoter used in these constructs is affected by exposure to high-light but there are no reports of this as a possible explanation. It is intriguing that the transcript abundance profile for ScELIP1 is more similar to the native Arabidopsis SEP2 and the transcript abundance profile for ScELIP2 is more similar to OHP2 than to other photosynthetic related transcripts. If the $35 \mathrm{~S}$ promoter, which is active in the untreated controls, is not high-light inducible then it could suggest the presence of a post-transcriptional mechanism that may control the abundance of the transcripts of three ELIP families of protective proteins. The transcript abundance profiles in response to both short and long exposure to high-light for all of the photosynthetic related transcripts in the genotypes we investigated were complex. However, it was evident that the Atelip mutant was, with the exception of the SEP2 transcript which was elevated above control levels (Figure 8f), deficient in proteins that function to protect PSII. The ectopic expression of the ScELIP transcripts in the Atelip mutant appears to provide the necessary protective proteins (at least the transcripts) which overcomes the high-light phenotype of the mutant. In addition, the transcript abundance profiles for all genes and genotypes indicate either a recovery of or elevation in transcript abundance after 3 weeks of exposure to high-light which may be indicative of the ability of Arabidopsis to acclimate to this environmental stress.

\section{Materials and Methods}

\subsection{Plant Material and Growth Conditions}

Dry Syntrichia caninervis gametophytes were collected from the Gurbantunggut Desert in the Xinjiang Uygur Autonomous Region, China ( $44^{\circ} 32^{\prime} 30^{\prime \prime} \mathrm{N}, 88^{\circ} 6^{\prime} 42^{\prime \prime} \mathrm{E}$ ) and kept in the dark in a paper sack at room temperature. Dry gametophytes were fully hydrated on filter paper saturated with MINIQ-filtered water $(8 \mathrm{~mL})$ in glass petri dishes for $24 \mathrm{~h}$ at $25^{\circ} \mathrm{C}$, with light at a photosynthetic photon flux density (PPFD) of $50 \mu \mathrm{mol} / \mathrm{m}^{2} / \mathrm{s}$, prior to the described light treatments.

Seeds of Arabidopsis thaliana L. cv. Columbia and the Arabidopsis mutant Atelip were germinated on MS medium [44] after surface sterilization with $70 \%$ ethanol for $30 \mathrm{~s}$ followed by $3 \%$ sodium hypochlorite for $7 \mathrm{~min}$ and washed 5 times with sterile water. Seedlings were transferred to $5 \mathrm{~cm}$ diameter pots at 4-6 leaf stage containing autoclaved peat substrate (Pindstrup, Mosebrug) and grown under controlled conditions at $22 \pm 2{ }^{\circ} \mathrm{C}$ with a $14 \mathrm{~h}$ light $/ 10 \mathrm{~h}$ dark cycle, $60-75 \%$ relative humidity, and light at PPFD of $100 \mu \mathrm{mol} / \mathrm{m}^{2} / \mathrm{s}$. A. thaliana (Col-0) and the mutant Atelip (NASC ID: N544166), a T-DNA insertion mutant in the promoter region of ELIP2 [45], were obtained from The European Arabidopsis Stock Centre.

\subsection{Bioinformatic Analysis of Syntrichia Caninervis ELIP Sequences}

Publicly available ELIP sequences of A. thaliana and Physcomitrella patens were used to screen the transcriptome of $S$. caninervis [10] for single copy transcripts (designated as unigenes) that were putative ELIP coding sequences. We translated each unigene to obtain the amino acid sequence using ORF finder. All generated amino acid sequences were investigated using NCBI-blastp. The final sequences used to construct the SCELIP clones were consistent with annotated ELIP genes in the NCBI database. A molecular phylogeny was constructed using MEGA7.0 with the neighbor-joining method and 500 bootstrap replicates [46] utilizing the eudicots, monocots, ferns, and bryophytes ELIP sequences obtained from public resources and presented in additional data (Table S2). All of ELIP genes domain prediction was conducted with the Pfam database (http://pfam.xfam.org/search). Further physiological and biochemical properties prediction for two ScELIPs was obtained on ExPASy (https://www.expasy.org/).

\subsection{Extraction of RNA and RT-qPCR Based Expression Analysis}

Total RNA was isolated from $0.1 \mathrm{~g}$ of $S$. caninervis gametophytes using the TRIzol reagent (Qiagen, Berlin, Germany) according to the manufacturer's protocol. The cDNA was synthesized 
from $1 \mu \mathrm{g}$ of total RNA using random hexamer primers with the PrimeScript RT reagent kit including gDNA Eraser (Real time; Takara, Japan) according to the manufacturer's protocol and stored at $-20{ }^{\circ} \mathrm{C}$ until use. The cDNA was diluted 10 -fold with $\mathrm{H}_{2} \mathrm{O}$ to serve as a template for Real-time PCR. Each $20 \mu \mathrm{L}$ real-time PCR reaction contained $2 \mu \mathrm{L}$ cDNA, $0.5 \mu \mathrm{L}$ each of forward and reverse primers as indicated below (10 $\mu \mathrm{M}$ for each primer), and $10 \mu \mathrm{L}$ of SYBR Premix Ex Taq ${ }^{\mathrm{TM}}$ (Takara Biomedical Technology, Takara, Japan). Real-time quantitative PCR was performed in 96-well plates with the CFX96 Real-Time PCR Detection System (Bio-Rad, New York, NY, USA) according to the manufacturer's instructions [47], with three technical replicates and two biological replicates. The RT-qPCR protocol was as follows: $30 \mathrm{~s}$ initial denaturation at $95^{\circ} \mathrm{C}, 40$ cycles of $94{ }^{\circ} \mathrm{C}$ for $5 \mathrm{~s}$, and $60^{\circ} \mathrm{C}$ for $30 \mathrm{~s}$. Parallel reactions to amplify $\alpha$-TUB2 were used to normalize the amount of template. The forward and reverse primers used for ScELIP1 were 5' GGCTATGCTGGGATTCGTGT $3^{\prime}$ and 5' TTGATCTGGTTCCTGGCGTC $3^{\prime}$, the primers for ScELIP2 were 5' GCAATGATCGGACTTGTCGC $3^{\prime}$ and $5^{\prime}$ ACCTGCTGTGAACAATCCGT $3^{\prime}$. All PCR efficiencies were $>95 \%$. Transcript abundance data were collected using Bio-Rad CFX Manager.

Hydrated S. caninervis gametophytes were exposed to the following environmental treatments: A progressive series of PPFD, Ultraviolet A (UVA), Ultraviolet B (UVB), red-light, and blue-light. Fully hydrated S. caninervis gametophytes were transferred to MINIQ-filtered water saturated filter paper in clean petri dishes for all treatments. The light series treatment consisted of a $2 \mathrm{~h}$ exposure to either $0 \mu \mathrm{mol} / \mathrm{m}^{2} / \mathrm{s}, 60 \mu \mathrm{mol} / \mathrm{m}^{2} / \mathrm{s}, 225 \mu \mathrm{mol} / \mathrm{m}^{2} / \mathrm{s}, 750 \mu \mathrm{mol} / \mathrm{m}^{2} / \mathrm{s}$, or $1500 \mu \mathrm{mol} / \mathrm{m}^{2} / \mathrm{s}$ provided by a cool-white fluorescent light lamp (Philips lighting). For the ultraviolet radiation treatment gametophytes were exposed to either UVA $(380 \mathrm{~nm})$ or UVB $(308 \mathrm{~nm})$ irradiation for $0 \mathrm{~h}, 1 \mathrm{~h}, 2 \mathrm{~h}$, $4 \mathrm{~h}, 12 \mathrm{~h}$ under a fluorescent light lamp (Philips lighting) that delivered a PPFD of $10 \mu \mathrm{mol} / \mathrm{m}^{2} / \mathrm{s}$. In the red-light treatment, gametophytes were either exposed to red-light using a monochromatic light-emitting diode (LED, Philips lighting, Amsterdam, Netherlands) at $655 \mathrm{~nm}$, and PPFD of $100 \mu \mathrm{mol} / \mathrm{m}^{2} / \mathrm{s}$ for $0,2,4 \mathrm{~h}$, or exposed to red-light for $2 \mathrm{~h}$ and then transferred to blue-light for $2 \mathrm{~h}$. In the blue-light treatment gametophytes were either exposed to blue-light using a monochromatic light-emitting diode (LED, Philips lighting) at $450 \mathrm{~nm}$ and PPFD of $100 \mu \mathrm{mol} / \mathrm{m}^{2} / \mathrm{s}$ for $0 \mathrm{~h}, 2 \mathrm{~h}, 4 \mathrm{~h}$, or exposed to blue-light for $2 \mathrm{~h}$ and then transferred to red-light for $2 \mathrm{~h}$. Each treatment consisted of three biological replicates.

\subsection{Cloning of ScELIP Genes and Establishment of Transgenic Lines}

The transcripts ScELIP1 (Unigene 40121) and ScELIP2 (Unigene 68225) were chosen from the Syntrichia caninervis transcriptome database [10]. The full-length coding sequence for each gene product was obtained by RT-PCR using the cDNA previously constructed for the RT-qPCR based expression analysis. The RT-PCR was performed using gene-specific primers: For ScELIP1 the forward and reverse primers were $5^{\prime}$ GGGGTACCC ATGGCAGCGATGGCG $3^{\prime}$ and $5^{\prime}$ CGAGATCTCGCTAGACAGGGAAGCG $3^{\prime}$, and these primers include inserted KpnI and Xball enzyme sequences. For ScELIP2, the forward and reverse primers were $5^{\prime}$ CGGGATCCATGGCGATGACTTT $3^{\prime}$ and 5' CGAGATCTCGTTATACAAGTGGGC $3^{\prime}$, and these primers include Bam HI and Xball site sequences. The PCR product was extracted from agarose gel electrophoresis $(0.8 \%$ agarose, $5 \mathrm{v} / \mathrm{cm}$ voltage for $20 \mathrm{~min}$ ) using the Gel Extraction Kit (OMEGA, St. Louis, MI, USA), and $4 \mu \mathrm{L}$ PCR extract production, $1 \mu \mathrm{L}$ pMD 19-T vector, $1 \mu \mathrm{L}$ T4 DNA ligase, $2 \mu \mathrm{L} 10 \times$ ligation buffer, and $12 \mu \mathrm{L} \mathrm{H}_{2} \mathrm{O}$ for $2 \mathrm{~h}$ (TaKaRa, Japan), linking the product with pMD 19-T vector. The sequences were validated by sanger sequencing at the Beijing Genomics Institute (BGI) to ensure that there were no PCR introduced mutations into the coding sequences.

\subsection{Transformation of A. Thaliana}

The ScELIP1 ORF was removed from ScELIP1-19T by digestion with KpnI and XbalI and cloned into KpnI and XbalI—digested pCAMBIA 1301 to construct a 35S-ScELIP1 gene (Figure S2). Likewise, the ScELIP2 ORF was removed from ScELIP1-19T by digestion with Bam HI and XbalI and cloned 
into BamHI and XbalI-digested pCAMBIA 1301 to construct a 35S-ScELIP2 gene (Figure S3). The pScELIP1-CAMBIA 1301 and pScELIP2-CAMBIA 1301 were introduced separately into an Agrobacterium tumefaciens strain EHA105 by triparental mating as described by Hoekema et al. [48] and introduced into 6-week old Arabidopsis ELIP mutant Atelip plants by the floral dip method [49]. $\mathrm{T} 1$ transgenic plants were selected by germination on MS agar plates containing Hygromycin $(80 \mathrm{mg} / \mathrm{L})$. After 7 days, the majority of the seedlings turn yellow or white and die. After 10 days, those seedlings that continued to stay green and grow were considered as stable transformants. The stable transformants were verified by PCR by using the same gene-specific primers used to isolate the coding sequences for each ScELIP. Primary transformants were shelfed to generate T2 homozygous transgenic seed stocks for production of T3 homozygous plants used in the phenotypic analysis.

\subsection{Seed Germination Assay}

Petri plates containing 1/2 MS agar media (1\%) were divided into four quadrants and approximately 50 seeds were sown of each genotype into separate quadrants: Arabidopsis Col-0 wildtype (WT), the Atelip mutant, and two transgenic Arabidopsis lines of ScELIP1 or ScELIP2. Seed germination, when the radicle protruded through the seed coat, was scored from the first day after sowing. The seed germination assay was conducted under standard conditions $\left(22 \pm 2{ }^{\circ} \mathrm{C}, 14 \mathrm{~h}\right.$ light $/ 10 \mathrm{~h}$ dark cycle, $60-75 \%$ relative humidity, and PPFD of $100 \mu \mathrm{mol} / \mathrm{m}^{2} / \mathrm{s}$ ) as a control or under the following treatments; irradiated by red, blue, UVB, or high-light $\left(1000 \mu \mathrm{mol} / \mathrm{m}^{2} / \mathrm{s}\right)$ as their single light source (as mentioned in 2.3 Extraction of RNA and RT-qPCR based expression analysis) at $22{ }^{\circ} \mathrm{C} 14 \mathrm{~h}$ light/ $10 \mathrm{~h}$ dark cycle for 6 days.

\subsection{Phenotypic Analysis of Transgenic A. Thaliana}

Sterile WT, Atelip mutant, and ScELIPs transgenic Arabidopsis seeds were vernalized for $2 \mathrm{~d}$ and germinated on $1 / 2 \mathrm{MS}$ agar medium under control conditions of $22^{\circ} \mathrm{C}$ and $14 \mathrm{hlight} / 10 \mathrm{~h}$ dark cycle and PPFD of $100 \mu \mathrm{mol} / \mathrm{m}^{2} / \mathrm{s}$. Seven-day old seedlings, of similar size, were chosen for exposure to experimental treatments. WT, Atelip mutant, and transgenic ScELIPs lines, were cultured on 1/2 MS medium for 7 days at $22^{\circ} \mathrm{C} 14 \mathrm{~h} \mathrm{light} / 10 \mathrm{~h}$ dark cycle. Individual light treatments were administered for 7 days at $22^{\circ} \mathrm{C} 14 \mathrm{~h}$ light $/ 10 \mathrm{~h}$ dark cycle and PPFD of $100 \mu \mathrm{mol} / \mathrm{m}^{2} / \mathrm{s}$ under the appropriate light source of either red, blue, or UVB as described for the gene expression study. After all treatments the number of leaves, roots, and the length of the longest root were recorded.

For the high-light treatment, seven-day-old seedling, grown under control conditions of $22{ }^{\circ} \mathrm{C}$ and $14 \mathrm{~h} \mathrm{light} / 10 \mathrm{~h}$ dark cycle and PPFD of $100 \mu \mathrm{mol} / \mathrm{m}^{2} / \mathrm{s}$, were briefly exposed to light at an intensity of $1500 \mu \mathrm{mol} / \mathrm{m}^{2} / \mathrm{s}$ for $2 \mathrm{~h}$ and subsequently transferred to normal conditions for $24 \mathrm{~h}$ to recover. Following recovery, the seedlings were assessed for chlorophyll content as described in a later section.

\subsection{High-Light Treatment of Plantlets}

Seedlings of WT, Atelip mutant, and ScELIPs transgenic lines of Arabidopsis were grown in $5 \mathrm{~cm}$ diameter pots in a peat substrate (Pindstrup, Mosebrug, Ryomgård, Denmark) and grown under well-watered controlled conditions at $22 \pm 2{ }^{\circ} \mathrm{C}$ with a $14 \mathrm{~h}$ light $/ 10 \mathrm{~h}$ dark cycle, PPFD of $100 \mu \mathrm{mol} / \mathrm{m}^{2} / \mathrm{s}$, and $60-75 \%$ relative humidity. After four weeks plants were irradiated with high-light $\left(1000 \mu \mathrm{mol} / \mathrm{m}^{2} / \mathrm{s}\right)$ at $22{ }^{\circ} \mathrm{C} 14 \mathrm{~h}$ light $/ 10 \mathrm{~h}$ dark cycle under well-watered conditions. $\mathrm{F}_{\mathrm{v}} / \mathrm{F}_{\mathrm{m}}$ was measured before treatment $(0 \mathrm{~h})$, after exposure to high-light for 3 days and then continuously for 3 weeks. Leaf samples were taken for chlorophyll and carotenoid analyses before and after 3 days and 3 weeks of high-light treatment.

The relative transcript abundance was assessed for ScELIP1, ScELIP2, One-Helix Protein (OHP), OHP2, two-helix protein (SEP2), PSII CP29 antenna protein (LHCB4.2), PSI antenna protein (LHCA2), PSII CP22 protein (PSBS), and PSII D2 protein (PSBD), after exposure to high-light for $0 \mathrm{~h}$ and $2 \mathrm{~h}$, 3 days and 3 weeks. Each treatment consisted of 3 biological replicates. The method of extraction of RNA and RT-qPCR based expression analysis was as stated previously. To compare relative expression levels, Col-0 WT and all ScELIPs transgenic lines of Arabidopsis were compared to the Atelip mutant, and $A t \alpha-T U B$ was used as a reference gene; primer sequences are listed in Table S3. 


\subsection{Pigment Analysis}

Chlorophyll content was measured according to the methods described by Ritchie 2006 [50]. Leaf samples (50 mg Fwt) were collected from three separate plants for each line and at each treatment phase. Pigments were extracted by incubation of the leaf samples in $2 \mathrm{~mL}$ of $96 \%$ ethanol (room temperature $\sim 25{ }^{\circ} \mathrm{C}$ ) for $4 \mathrm{~h}$ in darkness with constant agitation. The extracts were centrifuged at 10,000 rpm for $2 \mathrm{~min}$ and the supernatants removed for analysis. Supernatants were analyzed spectrophotometrically at wavelengths of 470,649 , and $665 \mathrm{~nm}$ using a UV-Visible spectrophotometer (Biomate 3S, Thermo Fisher Scientific, Waltham, MA, USA). The concentration of the chlorophyll a, b, and total carotenoids were determined using the following equations: $\mathrm{Chl} a=13.95 \times \mathrm{OD}_{665}-6.88 \times$ $\mathrm{OD}_{649}, \mathrm{Chl} \mathrm{b}=24.96 \times \mathrm{OD}_{649}-7.32 \times \mathrm{OD}_{665}$, and $\mathrm{Car}=\left(1000 \times \mathrm{OD}_{470}-2.05 \times \mathrm{Chl} \mathrm{a}-114.8 \times \mathrm{Chl} \mathrm{b}\right) / 245$. The total pigment content in $\mathrm{mg} / \mathrm{g}=\mathrm{N} \times \mathrm{C} \times \mathrm{V} / \mathrm{W}$, “ $\mathrm{N}$ " represents dilution ratio, " $\mathrm{C}$ " represents pigments concentration $(\mathrm{mg} / \mathrm{mL})$, "V" represents the volume of extracting solution $(\mathrm{mL})$, “ $\mathrm{W}$ " represents sample fresh weight $(\mathrm{g})$.

\subsection{Fluorometric Assessment of Photosynthetic Performance}

Photosynthetic performance of $S$. caninervis at a different light intensity and times were assessed by pulse amplitude modulated fluorometry using a portable chlorophyll fluorometer (PAM 2500) (Heinz, Walz, Berlin, Germany). Measurements of chlorophyll fluorescence were recorded in situ on the mid portion of the uppermost fully mature leaf. The saturation pulse method was used to calculate the $\mathrm{F}_{\mathrm{v}} / \mathrm{F}_{\mathrm{m}}$, the parameter settings were based on the recommendations of Zhang et al. [51]. All parameters were measured on 6 individual plants and the values were averaged for each genotype.

\subsection{Statistical Analyses}

All statistical analyses were performed using Statistical Product and Service Solutions (SPSS) 16.0 software (SPSS Inc., Chicago, IL, USA). Data were compared using one-way ANOVA, Dunnett's T3 was used to examine the difference in significance of ANOVA results, and values were considered as significantly statistically different at $p<0.05$, or distinctly statistically different at $p<0.01$. Error bars represent standard deviations.

\section{Conclusions}

In Syntrichia caninervis, ScELIP1 and ScELIP2 transcript abundance were activated by multiple light stresses, especially increasing high-light intensity. Expression of ScELIPs in the Atelip mutant increase germination rates but the rates do not attain WT rates when grown in red, blue, UVB, and high-light conditions. Different light quality changed morphology after the germination and seedling stage, while this phenotype was not altered between Col-0 WT, Atelip mutant, and 35S-ScELIPs transgenic lines. Two ScELIPs can protect chlorophyll and accumulation of photoprotective pigments such as carotenoid under high-light stress. High-light leads to transcriptional suppression of genes encoding antenna proteins such as LHCA2, LHCB4.2, PSBS at $2 \mathrm{~h}$ and 3 days, but slightly increases at 3 weeks. High-light causes transcriptional activation of genes encoding proteins responsible for photoprotection, such as SCELIP1 and SCELIP2 and 3 of the AtELIP family (OHP, OHP2, SEP2). These findings can clarify the process of ELIPs of bryophyte response to different light quality and/or intensity especially to high-light and is important for land plant evolutionary adaptation.

Supplementary Materials: Supplementary materials can be found at http://www.mdpi.com/1422-0067/21/4/ 1411/s1. Table S1. Properties of 6 ScELIPs Unigenes. Table S2. Sequences information for construction of the phylogenetic tree. Table S3. Primer information for RT-qPCR of high light treatment of plantlets. Figure S1. The amino acid sequences alignment of ELIPs by MEGA 7.0. Figure S2. 35S-ScELIP1 vector construction strategy. Figure S3. 35S-ScELIP2 vector construction strategy. Figure S5. Hygromycin selection of transgeneic Arabidopsis thaliana. Figure S6. RT-PCR validation of T3 transgenic lines. Figure S7. Quantitative real time PCR expression level analysis of ScELIP1 and ScELIP2 transgenic lines. Figure S8. Seed germination phenotypes for Col-0 WT, Atelip mutant and 35S-ScELIP lines under different light treatments. Figure S9. Phenotypic response of Col-0 WT, Atelip mutant and 35S-ScELIP1 and 35S-ScELIP2 after seven days of exposure to different light treatments. 
Figure S10. The change of chlorophyll content of WT, Atelip and transgenic lines at $0 \mathrm{~h}, 3$ days and 3 weeks high light stress $(1000 \mu \mathrm{mol} / \mathrm{m} 2 / \mathrm{s})$.

Author Contributions: Conceptualization, X.L. and D.Z.; methodology, H.Y.; software, X.L.; validation, X.L. and Y.L.; formal analysis, Y.Z.; investigation, X.L. and Y.Z.; data curation, H.Y.; writing-original draft preparation, X.L.; writing-review and editing, D.Z. and M.J.O.; visualization, D.Z.; supervision, D.Z. All authors have read and agreed to the published version of the manuscript.

Funding: This research was funded by NSFC (National Natural Science Foundation of China)-Xinjiang key project number U1703233 and NSFC grant number 31870318, and The Introduction Project of High-level Talents in Xinjiang Uygur Autonomous Region, as well as the National Science Foundation (Collaborative Research: Dimensions: Grant number 1638972 to M.J.O.).

Acknowledgments: We are grateful to M.J.O. for critical comments and valuable suggestions to the manuscript and NASC (Eurasian Arabidopsis stock centre) for providing the seed of Arabidopsis Atelip mutant.

Conflicts of Interest: The authors declare no conflict of interest. The funders had no role in the design of the study; in the collection, analyses, or interpretation of data; in the writing of the manuscript, or in the decision to publish the results.

\section{References}

1. Li, Z.R.; Wakao, S.; Fischer, B.B.; Niyogi, K.K. Sensing and Responding to Excess Light. Annu. Rev. Plant Biol. 2009, 60, 239-260. [CrossRef] [PubMed]

2. Gill, S.S.; Tuteja, N. Reactive oxygen species and antioxidant machinery in abiotic stress tolerance in crop plants. Plant Physiol. Biochem. 2010, 48, 909-930. [CrossRef] [PubMed]

3. Demmig Adams, B.; Adams, W.W. Photoprotection and other responses of plants to high light stress. Annu. Rev. Plant Phys. 1992, 43, 599-626. [CrossRef]

4. Choudhury, N.K.; Behera, R.K. Photoinhibition of photosynthesis: Role of carotenoids in photoprotection of chloroplast constituents. Photosynthetica 2001, 39, 481-488. [CrossRef]

5. Yamakawa, H.; Itoh, S. Dissipation of Excess Excitation Energy by Drought-Induced Nonphotochemical Quenching in Two Species of Drought-Tolerant Moss: Desiccation-Induced Acceleration of Photosystem II Fluorescence Decay. Biochemistry 2013, 52, 4451-4459. [CrossRef] [PubMed]

6. Stark, L.R.; Greenwood, J.L.; Brinda, J.C.; Oliver, M.J. The desert moss Pterygoneurum lamellatum (Pottiaceae) exhibits an inducible ecological strategy of deciccation toterance: Effects of rate of dying on shoot damage and regenertion. Am. J. Bot. 2013, 100, 1522-1531. [CrossRef]

7. Zhang, Y.M.; Chen, J.; Wang, L.; Wang, X.Q.; Gu, Z.H. The spatial distribution patterns of biological soil crusts in the Gurbantunggut Desert, Northern Xinjiang, China. J. Arid Environ. 2007, 68, 599-610. [CrossRef]

8. Li, J.H.; Li, X.R.; Chen, C.Y. Degradation and reorganization of thylakoid protein complexes of Bryum argenteum in response to dehydration and rehydration. Bryologist 2014, 117, 110-118. [CrossRef]

9. Gao, B.; Li, X.S.; Zhang, D.Y.; Liang, Y.Q.; Yang, H.L.; Chen, M.X.; Zhang, Y.M.; Zhang, J.H.; Wood, A.J. Desiccation tolerance in bryophytes: The dehydration and rehydration transcriptomes in the desiccation-tolerant bryophyte Bryum argenteum. Sci. Rep. 2017, 7, 7571-7584. [CrossRef]

10. Gao, B.; Zhang, D.; Li, X.; Yang, H.; Wood, A.J. De novo assembly and characterization of the transcriptome in the desiccation-tolerant moss Syntrichia caninervis. BMC Res. Notes 2014, 7, 490. [CrossRef]

11. Proctor, M.C.F.; Oliver, M.J.; Wood, A.J.; Alpert, P.; Stark, L.R.; Cleavitt, N.L.; Mishler, B.D. Desiccation-tolerance in bryophytes: A review. Bryologist 2007, 110, 595-621. [CrossRef]

12. Li, Y.; Wang, Z.B.; Xu, T.H.; Tu, W.F.; Liu, C.; Zhang, Y.M.; Yang, C.H. Reorganization of photosystem II is involved in the rapid photosynthetic recovery of desert moss Syntrichia caninervis upon rehydration. J. Plant Physiol. 2010, 167, 1390-1397. [CrossRef] [PubMed]

13. Hutin, C.; Nussaume, L.; Moise, N.; Moya, I.; Kloppstech, K.; Havaux, M. Early light-induced proteins protect Arabidopsis from photooxidative stress. Proc. Natl. Acad. Sci. USA 2003, 100, 4921-4926. [CrossRef] [PubMed]

14. Meyer, G.; Kloppstech, K. A Rapidly Light-Induced Chloroplast Protein with a High Turnover Coded for by Pea Nuclear-DNA. Eur J. Biochem. 1984, 138, 201-207. [CrossRef]

15. Grimm, B.; Kloppstech, K. The early light-inducible proteins of Barley characterization of 2 families of 2-h-specific nuclear-coded chloroplast proteins. Eur J. Biochem 1987, 167, 493-499. [CrossRef] 
16. Adamska, I. The Elip family of stress proteins in the thylakoid membranes of pro- and eukaryota. Regul. Photosynth. 2001, 11, 487-505.

17. Rizza, A.; Boccaccini, A.; Lopez-Vidriero, I.; Costantino, P.; Vittorioso, P. Inactivation of the ELIP1 and ELIP2 genes affects Arabidopsis seed germination. New Phytol. 2011, 190, 896-905. [CrossRef]

18. Harari-Steinberg, O.; Ohad, I.; Chamovitz, D.A. Dissection of the light signal transduction pathways regulating the two early light-induced protein genes in Arabidopsis. Plant. Physiol. 2001, 127, 986-997. [CrossRef]

19. Montane, M.H.; Kloppstech, K. The family of light-harvesting-related proteins (LHCs, ELIPs, HLIPs): Was the harvesting of light their primary function? Gene 2000, 258, 1-8. [CrossRef]

20. Chen, C.; Bai, L.H.; Qiao, D.R.; Xu, H.; Dong, G.L.; Ruan, K.; Huang, F.; Cao, Y. Cloning and expression study of a putative carotene biosynthesis related $(c b r)$ gene from the halotolerant green alga Dunaliella salina. Mol. Biol. Rep. 2008, 35, 321-327. [CrossRef]

21. Zeng, O.; Chen, X.B.; Wood, A.J. Two early light-indudible protein (ELIP) cDNAs from the resurrection plant Tortula ruralis are differentially expressed in response to desiccation, rehydration, salinity, and high light. J. Exp. Bot. 2002, 53, 1197-1205. [CrossRef] [PubMed]

22. Rensing, S.A.; Lang, D.; Zimmer, A.D.; Terry, A.; Salamov, A.; Shapiro, H.; Nishiyama, T.; Perroud, P.F.; Lindquist, E.A.; Kamisugi, Y.; et al. The Physcomitrella genome reveals evolutionary insights into the conquest of land by plants. Science 2008, 319, 64-69. [CrossRef] [PubMed]

23. Adamska, I.; Ohad, I.; Kloppstech, K. Synthesis of the early light-inducible protein is controlled by blue-light and related to light stress. Proc. Natl. Acad. Sci. USA 1992, 89, 2610-2613. [CrossRef] [PubMed]

24. Adamska, I.; Kloppstech, K. Low temperature increases the abundance of early light-inducible transcript under light stress conditions. J. Biol. Chem. 1994, 269, 30221-30226. [PubMed]

25. Humbeck, K.; Kloppstech, K.; Krupinska, K. Expression of early light-inducible proteins in flag leaves of field-crown barley. Plant. Physiol. 1994, 105, 1217-1222. [CrossRef]

26. Heddad, M.; Adamska, I. Light stress-regulated two-helix proteins in Arabidopsis thaliana related to the chlorophyll a/b-binding gene family. Proc. Natl. Acad. Sci. USA 2000, 97, 3741-3746. [CrossRef]

27. Shimosaka, E.; Sasanuma, T.; Handa, H. A wheat cold-regulated cDNA encoding an early light-inducible protein (ELIP): Its structure, expression and chromosomal location. Plant. Cell Physiol. 1999, 40, 319-325. [CrossRef]

28. Bartels, D.; Hanke, C.; Schneider, K.; Michel, D.; Salamini, F. A desiccation-related ELIP-like gene from the resurrection plant craterostigma-plantagineum is regulated by light and ABA. Embo J. 1992, 11, 2771-2778. [CrossRef]

29. Montane, M.H.; Dreyer, S.; Triantaphylides, C.; Kloppstech, K. Early light-inducible proteins during long-term acclimation of barley to photooxidative stress caused by light and cold: High level of accumulation by posttranscriptional regulation. Planta 1997, 202, 293-302. [CrossRef]

30. Pinto, F.; Berti, M.; Olivares, D.; Sierralta, W.D.; Hinrichsen, P.; Pinto, M. Leaf development, temperature and light stress control of the expression of early light-inducible proteins (ELIPs). Vitis vinifera L. Environ. Exp. Bot. 2011, 72, 278-283. [CrossRef]

31. Lee, J.; Kim, T.J.; Lim, Y.P.; Bang, J.W.; Hur, Y. Molecular cloning and characterization of an early light-inducible gene, BrELIP, from Brassica rapa, and its overexpression protects Arabidopsis. Korean J. Genet. 2006, 28, 207-220.

32. Zhuo, C.L.; Cai, J.L.; Guo, Z.F. Overexpression of Early Light-Induced Protein (ELIP) Gene from Medicago sativa ssp. falcata Increases Tolerance to Abiotic Stresses. Agron. J. 2013, 105, 1433-1440. [CrossRef]

33. VanBuren, R.; Pardo, J.; Wai, C.M.; Evans, S.; Bartels, D. Massive tandem proliferation of ELIPs supports convergent evolution of desiccation tolerance across land plants. Plant. Physiol. 2019, 179, 1040-1049. [CrossRef] [PubMed]

34. Green, B.R.; Kuhlbrandt, W. Sequence conservation of light-harvesting and stress-response proteins in relation to the 3-dimensional molecular-structure of LHCII. Photosynth. Res. 1995, 44, 139-148. [CrossRef] [PubMed]

35. Alexandrov, N.N.; Brover, V.V.; Freidin, S.; Troukhan, M.E.; Tatarinova, T.V.; Zhang, H.Y.; Swaller, T.J.; Lu, Y.P.; Bouck, J.; Flavell, R.B.; et al. Insights into corn genes derived from large-scale cDNA sequencing. Plant. Mol. Biol. 2009, 69, 179-194. [CrossRef] [PubMed]

36. Adamska, I.; Kloppstech, K.; Ohad, I. UV-light stress induces the synthesis of the early light-inducible protein and prevent its degradation. J. Biol. Chem. 1992, 267, 24732-24737. [PubMed] 
37. Wang, H.L.; Cao, F.L.; Li, G.P.; Yu, W.W.; Aitken, S.N. The transcript profiles of a putative early light-induced protein (ELIP) encoding gene in Ginkgo biloba L. under various stress conditions. Acta Physiol Plant 2015, 37, 1720-1732. [CrossRef]

38. Hayami, N.; Sakai, Y.; Kimura, M.; Saito, T.; Tokizawa, M.; Iuchi, S.; Kurihara, Y.; Matsui, M.; Nomoto, M.; Tada, Y.; et al. The Responses of Arabidopsis Early Light-Induced Protein2 to Ultraviolet B, High Light, and Cold Stress Are Regulated by a Transcriptional Regulatory Unit Composed of Two Elements. Plant. Physiol. 2015, 169, 840-855. [CrossRef]

39. Jansson, S. A guide to the Lhc genes and their relatives in Arabidopsis. Trends Plant. Sci. 1999, 4, $236-240$. [CrossRef]

40. Rossel, J.B.; Wilson, I.W.; Pogson, B.J. Global changes in gene expression in response to high light in Arabidopsis. Plant Physiol. 2002, 130, 1109-1120. [CrossRef]

41. Li, J.G.; Yang, L.; Jin, D.; Nezames, C.D.; Terzaghi, W.; Deng, X.W. UV-B-induced photomorphogenesis in Arabidopsis. Protein Cell 2013, 4, 485-492. [CrossRef] [PubMed]

42. Sharma, A.; Sharma, B.; Hayes, S.; Kerner, K.; Hoecker, U.; Jenkins, G.I.; Franklin, K.A. UVR8 disrupts stabilisation of PIF5 by COP1 to inhibit plant stem elongation in sunlight. Nat. Commun. 2019, 10, 4417-4426. [CrossRef] [PubMed]

43. Adamska, I.; Kloppstech, K.; Ohad, I. Early light-inducible protein in pea is stable during light stress but is degraded during recovery at low light-intensity. J. Biol. Chem. 1993, 268, 5438-5444. [PubMed]

44. Linsmaier, E.M.; Skoog, F. Organic Growth Factor Requirements of Tobacco Tissue Cultures. Physiol. Plant. 1965, 18, 100-127. [CrossRef]

45. Alonso, J.M.; Stepanova, A.N.; Leisse, T.J.; Kim, C.J.; Chen, H.M.; Shinn, P.; Stevenson, D.K.; Zimmerman, J.; Barajas, P.; Cheuk, R.; et al. Genome-wide Insertional mutagenesis of Arab. thaliana. Science 2003, 301, 653-657. [CrossRef]

46. Kumar, S.; Nei, M.; Dudley, J.; Tamura, K. MEGA: A biologist-centric software for evolutionary analysis of DNA and protein sequences. Brief. Bioinform. 2008, 9, 299-306. [CrossRef]

47. Bustin, S.A.; Benes, V.; Garson, J.A.; Hellemans, J.; Huggett, J.; Kubista, M.; Mueller, R.; Nolan, T.; Pfaffl, M.W.; Shipley, G.L.; et al. The MIQE Guidelines: Minimum Information for Publication of Quantitative Real-Time PCR Experiments. Clin. Chem. 2009, 55, 611-622. [CrossRef]

48. Hoekema, A.; Hirsch, P.R.; Hooykaas, P.J.J.; Schilperoort, R.A. A Binary Plant Vector Strategy Based on Separation of Vir-Region and T-Region of the Agrobacterium-Tumefaciens Ti-Plasmid. Nature 1983, 303, 179-180. [CrossRef]

49. Clough, S.J.; Bent, A.F. Floral dip: A simplified method for Agrobacterium-mediated transformation of Arab. thaliana. Plant. J. 1998, 16, 735-743. [CrossRef]

50. Ritchie, R.J. Consistent sets of spectrophotometric chlorophyll equations for acetone, methanol and ethanol solvents. Photosynth. Res. 2006, 89, 27-41. [CrossRef]

51. Zhang, J.; Zhang, Y.M.; Downing, A.; Wu, N.; Zhang, B.C. Photosynthetic and cytological recovery on remoistening Syntrichia caninervis Mitt., a desiccation-tolerant moss from Northwestern China. Photosynthetica 2011, 49, 13-20. [CrossRef]

(C) 2020 by the authors. Licensee MDPI, Basel, Switzerland. This article is an open access article distributed under the terms and conditions of the Creative Commons Attribution (CC BY) license (http://creativecommons.org/licenses/by/4.0/). 